\title{
Territorial Recreational Systems and Sustainable Development
}

\author{
Liudmyla Arkhypova* \\ Head of Tourism Department, \\ Ivano-Frankivsk National Technical \\ University of Oil and Gas \\ Ivano-Frankivsk, Ukraine \\ e-mail:konsevich@ukr.net
}

\author{
Natalia Fomenko \\ Associate Professor of the Department \\ of Geography and Natural Sciences \\ Stefanyk Precarpathian National \\ University \\ Ivano-Frankivsk, Ukraine \\ e-mail:nataly.fmnk@gmail.com \\ Olena Golovnia \\ Associate Professor the Department of \\ International Management, hotel and \\ restaurant business and tourism, \\ Vinnytsia National Agrarian \\ University, \\ Vinnytsa, Ukraine \\ e-mail:ellens@meta.ua
}

\author{
Iryna Kinash \\ Professor, Department of Management \\ and Administration, \\ Ivano-Frankivsk National Technical \\ University of Oil and Gas \\ Ivano-Frankivsk, Ukraine \\ e-mail: : irinakinash@gmail.com
}

\begin{abstract}
- in this paper, the functional properties of the recreational environment are substantiated using the example of biosphere ecological concept and ecosystem's framework approach for the sustainable development of territorial recreation systems (TRS). In the issue of the sustainable development of TRS, its makes sense to study the dynamic processes in the prism of natural and man-made systems. Under the natural-technogenic system, the authors understands the dynamic spatiotemporal range of both natural and anthropogenic materials and processes, through which the exchange of matter and energy in the local systems, including recreation ones, occurs. According to the authors, the buffer capacity of recreation system is the dominant factor determining the prospects for the sustainable development of TRS. The combination of theoretical and methodological foundations of the doctrine of functionally integral geosystems with the concept of multi-vector nature of recreational environment formation, allowed pointing out and specifying those TRS, which operate within a certain space. TRS, according to the authors is a dynamic set with the purpose of anthropogenic subjects and processes recreation within Geosystems whose activities continually trigger environmental changes, quantitative and qualitative Geosystem parameters, and is under the influence of man-made changes. The sustainable development of TRS provides an organization of recreational activities in which territorial Geosystem does not go beyond homeostasis and increasing of a recreational load is limited by buffer capacity of TRS. In this paper, the mathematical formalization of sustainable development of TRS is suggested. It can be used for the following definition of the subject of research: territorial recreational system that operates in the environment, is the set of subjects that formed from a set of internal components interconnected with each other and with the environment by set of connections which vary in the process of sustainable development in time and space according to the set of functions.
\end{abstract}

Keywords - sustainable development, territorial recreation system, mathematical formalization

\section{INTRODUCTION}

Current stage of Ukraine's development is characterized by expansion of recreation activity which anticipates growing of capacity and efficiency in environmental-related activity within TRS. The most present scientific and technological solutions for environmental protection and optimization of technical and technological factors are sector-specific. Common scientific base in case of broadside approach is absent. The main disadvantage is a lack of systemic approach in the scientific solution of TRS steady development. Modern situation in ecosystem and environment of Carpathian region makes changes in standpoint about tourism development and technical progress. They have to be assessed in the light of ecological priority, presence of ecological risks and technogenic safety.

The problem of recreation sphere expanding with the aim of national policy realization in the sphere of constant social and economic development of communities has been developed by numerous of scientists for more than twenty years. The topicality of chosen problem in the global context was represented in results of set international meetings. For instance, "United Nations Millennium Declaration" carried by United Nations General Assembly on 8th September 2000, United Nations Conference on Sustainable Development "Rio+20" (Rio de Janeiro, Brazil, 20-22 June 2012) etc. That is why elaboration of the sustainable development strategy of territorial recreation systems (TRS) is currently central, especially for the biggest Ukrainian recreation region - Carpathian region $[1,2]$.

\section{AIM}

The aim of the paper:

- substantiate existing of a strong connection between traditional geographical viewpoint of TRS which arose at the end of XIX century on the one side and technogenic and ecological laws of development 
which trigger tranformation and development of TRS on the other;

- is to substantiate functional peculiarities of recreation environment in terms of biospheric and ecological conception as well as ecosystem and structural approach for the sustainable development of territorial recreation systems (TRS);

- to suggest mathematical formalization of TRS.

\section{LITERATURE REVIEW}

Development of tourism in the context of sustainable development Strategy was studied by M. Pedrana, Andreas Freytag \& Christoph Vietze, Tiberiu Cristian Avramescu, Ioan Franc, Valeriu \& Istoc, Elena Manuela, V. K. Babarytska, O. O. Lyubitseva, T. I. Tkachenko, I.V. Smal, V. V. Smal, L. M. Cherchik etc. A substantial contribution to some theories of sustainable development was made by G. P. Andreeva, M. P. Butko, O.A. Vorobjev, Y.Y. Hurbyk, O.Yu. Husljakov, V. M. Dmytrenko, P. V. Zacharchenko, O.V. Kafarskiy, H. M. Medjanyk, O. H. Rozmetova, N.V. Jatsuk etc. Despite importance and value of conducted researches, ecosystem approaches to sustainable development remain incomplete.

The main subject of recreation geography is territorial recreation systems (TRS). The most known definitions of this notion, in the author's opinion, are combined by geo ecosystem which is the most valuable component of recreational needs accommodation. At least, increasing of ecological risks and decreasing of the technogenic safety of recreation system depreciate touristic structure. According to V. S. Preobragenskiy, TRS is "social geographical system consisted of interrelated subsystems such as natural and cultural complexes, engineering buildings, operating personnel, control unit and tourists (recreants), and characterized by functional and territorial entirety" [3]. TRS by $\mathrm{O}$. V. Ilyina's definition is an object of recreational geography studying and complex geosystem which combine social, technogenic, natural components. It is considered alongside with territorial manufacturing units and natural geosystems [4]. I. V. Smal gives the following definition: "complex, dynamic, hierarchically organized and interrelated group of components which evolution and functioning deal with restoring of human forces and satisfaction its social needs" [5]. According to O. O. Beydyk definition, TRS is complex geosystem which combines social, technogenic and natural components. It is considered alongside with territorial manufacturing units and natural geosystems. It is controlled, often self-controlled system which consists of interrelated subsystems such as tourists, natural and cultural complexes, engineering buildings, control unit and operating personnel [6].

\section{RESULTS}

The object of study recreational geography is territorial recreational systems (TRS). Let's take a detailed look at the definition of TRS submitted by different authors. Russian geographer Professor Preobrazhensky was among the first scientists to define TRS in his book "Territorial recreational system as an object of geographical studies" [3]. In definition he clearly outlines spatiography of TRS, emphasizing its sociality as well as isolating subsystems such as natural and cultural complexes, engineering structures, staff, governing body and the rest (of tourists). A similar definition holds Ukrainian professor of geography Beydyk. Despite the common points of view of both authors, professor Beydyk allots to TRS "man-made" feature and he places TRS on a par with production systems, which gives us the right to think about a link between spatiography and ecological compatibility of the studied object: "... complex ... controlled, partially self-governing system is considered on a par with regional industrial complex ..." [6].

Further definitions of modern scientists are similar to each other. They have not only geographical but also social, technogenic and ecological component [4, 5]. Professor Maslyak emphasizes the "ecological compatibility" by the term "resources". He says: "territorial recreational system is a kind of spatially organized recreational facilities at the territory of a particular set of taxonomic rank, which operates on the basis of the resources of this area geographically and spatially connected with each other."

The concept of a territorial recreational system was not found in other literature. Often the term 'recreation' can be seen in phrases such as recreation and leisure, outdoor recreation, public recreation, recreation and sports, therapeutic recreation, recreation in parks etc. However, when analyzing the scientific literature of other countries, we found terms that make it possible to reduce the process of outdoor activities to existing of a system (including environmental, technological or such, which deals with the issue of sustainable development) to some extent. It can be proved while reading the literature, where the common phrases recreation and sustainability, recreation as a multifaceted delivery system, recreation and socioeconomic class, recreation and leisure service areas are used [7].

As it can be seen, nearly all definitions of TRS are combined, according to the authors, by geo-ecosystem basis which is the most important component necessary for the recreational needs. At least increasing of environmental risks and reducing of an environmental and technical safety depreciates the superstructure of a recreational tourism. TRS is no longer a purely geographical system because of manmade components included, so technogenic, biosphere and ecological characteristics can be applied.

Considering the object of recreation geography from the systems theory standpoint, any recreation system may be presented by complex of interrelated social, cultural, technical and natural spheres so it is an information system. Taking into account systematicity of the object, it can be considered as a dialectical unit of internal material, processing and functional subsystems [8].

A process repeating in a recreational system is triggered by cyclicity of natural factors. An integral characteristic of such influence is buffering capacity [9]. Today anthropogenic activity on an environment is quite substantial. That's why, in the authors' opinion, the buffering capacity of a recreational system is the main factor, which determinates further sustainable development of TRS.

During last more than a hundred years, an influence of natural factors has been decreasing but the impact of 
anthropogenic ones has been increasing, so new man-made classes of chemical substances, which cyclicity does not correspond to the natural rhythms, have appeared [10]. Thus, they can not be considered as simply natural formations. The problem of sustainable development of TRS needs studying of processes dynamic in terms of natural and technogenic systems. The natural and technogenic system is considered by the authors as the spatiotemporal complex of material substances and both natural and anthropogenic processes. By virtue of them, within the territorial systems, including recreational ones, the exchange of material substances and energy occurs. Besides natural formations, anthropogenic elements are parts of these systems too (for instance, tourists infrastructure) as well as elements of the recreational environment which state, content, and peculiarities are changed under anthropogenic influence. In such systems interactions between natural and artificial items (buildings) occur resulting in changing of TRS state. TRS are dynamic, open and quasi-equilibrium systems. Changing the structure of the recreational environment and creating artificial elements of the system, a Human being tries not only to manage this system based on previous explorations and calculations but willings to anticipate its functioning, intensity, changes in interactions of its elements and structure. Thus, TRS refers to such group of ecosystems which are considered by recreational geography with the aim of balanced stable ecological management of natural recourses.

Understanding of spatiotemporal character of TRS variability is a key for different approaches in sustainable TRS development investigation. For instance, regional development (spatial variability), dynamic (temporary variability), retrospective etc. Exploration of TRS is based on its peculiarities. According to the first principle of the general theory of systems, any system is heterogenous. It consists of different subsystems, blocks, their combinations and finally, of elements. According to the second principle, in each system combination of its primary elements or their parts takes place. Such combination happens in one or several ways by one or several laws of composition. For studying TRS it is essential to be able to outline their simple elements. Points of TRS classification depend on emphases laid to social, cultural, abiotic, biotic, technogenic components. As a result, "topogenous" and "cenogenetic" approaches have appeared. Usually, bigger units made out due to topogenous characteristics and smaller units due to cenogenetic ones [11]. Authors propose using the topogenous principle of TRS classification with emphasis on anthropogenic and abiotic units which trigger existing and changing in the biotic unit. One of the most important characteristics of TRS is its hierarchical organization.

TRS refer to complex systems so for their analysis alternatives have to be chosen [12] and as a result, TRS dynamic can be absolutely unpredictable. It's impossible to predict the further state of TRS based on current one only. We can point out the general area where TRS will be situated but identification of the particular point is quite difficult. In the scientific literature the principle of "contraintuitive behavior" is formed. It means that complex system reacts on impact factors in different, unexpected way [13] which can explain problems with sustainable prognosis formation.
What can be considered as an indivisible unit, as the item of TRS, studying of which can be neglected according to the system approach? V. D. Fedorov and T. G. Hylmanov [11] made a point that functional clustering is more important for the understanding of integral peculiarities of an ecosystem than a concept of population, which can be quite heterogeneous. The ecosystem is complex composition of both living and nonliving (inert) units. Usually, these units are considered separately as main factors of TRS [14]. For instance, environmental factors like air temperature, peculiarities of soil etc. can be considered in terms of an abiotic unit and biological species can be used for biotic unit description. Nevertheless, factors, in particular, are measured for investigations of TRS. Their qualitative analysis is used for further calculations and model's development. Many scientists think that the most important thing in the system is a presence of interactions between elements but not their identity $[9,15]$. Complete replacement of elements can occur in the system but it continues to persist if succession between elements and links is keeping. The same will be correct for TRS: their elements can change, but recreation system continues to persist.

Setting up an experiment on TRS is quite difficult due to size, complexity and its unique character so the specific method of their exploration is mathematical modeling. V. D. Fedorov [11] refers such systems to so-called random type (r-type), wherein essential role belongs to stochastic effects. He points out such systems are governed by case.

Exploration of sustainable TRS development should be based on the following ecological conceptual foundations [16], established in the process of scientific development: ecological concept, levels of organization concept, concept of "key" factors, trophic chains and networks concept, concept of stability, tolerance concept, concept of ecological dominance, concept of ecological diversity etc.

During studying of TRS it's necessary to pay attention to their content, structure, and functions (behavior). Nevertheless, some scientists include content into the term of structure [17]. In addition to it, there are three approaches to the understanding of structure: structure as a synonym of content, structure as a synonym of formation and structure as complex of connections $[8,9]$.

Typically, the structure is defined as a complex of connections between components $[12,18]$. Authors of the present article subscribe to the opinion of researchers convinced that structure is a complex of those components of the system which are essential from the standpoint of conducted exploration and those which have invariability at the whole interval of functioning, interesting for the researcher or at the every nonoverlapping subset included into the interval of functioning. The last one specification allows considering the sustainable development of TRS among "systems with a changeable structure".

Based more on practical studying of the sustainable development, than philosophy thinking, the author defines a structure as a complex of heterogeneous subject characteristics. They belong to the three aspects: the ratio between certain components, interrelation between components, changing of components and the subject at large. Authors convinced that for the prospects of 
exploration of the sustainable development of TRS, their structure gives much more information than dynamics of recreants and the state of an environment.

TRS are open type systems; their peculiarities and structure are determined by external, in relation to them, environment (exo-system processes) as well as by internal (endo-system) ones.

For TRS it's necessary to separate external and internal structures of the system. The internal system is a ratio between system's elements while the external one is external relations of the system and an environment. System's environment is an array of factors which influence on the system and an array of those subjects those characteristics can be changed due to system's functioning. Studying of the system's external environment is important from the Hedel's theory point of view, who suggested that every TRS has those peculiarities which can not be explained by exploration of a certain system only [19].

Distinguishing of structures depend on their peculiarities. We suggest the following differentiation of the structures: taxonomic, size, genetic, temporal, spatial, information, trophic, energy, ecological etc. This list is not full and it isn't the structures classification because they are distinguished based on different reasons. Some structures can be considered as a specific case of another one but during exploration of the system's sustainable development the structures from the present list are studied.

We will not labor the point of studying all the structures mentioned above but dip into some subjects. Studying temporal and spatial structures it's necessary to pay attention to the notion of size because all conclusions made about TRS depend on the size they are studied in.

According to the principle of the functional and entire system, TRS is distinguished as a volume capacity; geosystem is a framework of its formation. The combination of theoretical and methodological basics of concept about functional and entire Geosystem [17] with the concept of the polyfactorial character of recreation environment formation allows determining TRS functioning within certain spatial limits.

Distinguishing of TRS in terms of suggested approach is possible within the territory which can be studied as macrosystem consisting of numerous of elementary TRS. TRS is the unique form of existing and moving of matter within certain spatiotemporal limits so dynamic state of the system in all aspects is its native attribute. The main reason of the TRS dynamic as an open system is instability of external factors forming it. Any external impact on the TRS is an impulse to the matter and energy transformation as well as dynamic processes in the recreational environment.

TRS is capable reacting fast to a changeable environment by dynamic, structural, functional transformations or by variations in its matter and energy structure. That's why when certain events happen in the environment but do not reach a significant threshold, TRS reflects by spatiotemporal reorganization of its structure. If a resultant outcome doesn't reach the upper threshold and is in homeostasis limits, the system's transformation is temporal and after some time it returns to the initial stable position. If a resultant outcome exceeds the upper threshold, the system's transformation is irreversible and is beyond the homeostasis limits. This absolute threshold can be modeled using the index of anthropogenic influence which includes both qualitative and quantitative factors of natural and technogenic impact [2].

Steadiness of TRS lies in the keeping of equilibrium state of its natural component during whole a period if affecting factors remain stable. In a case when any factor has an impact on TRS's geosystem basis, it will respond to it in accordance with the physical and chemical laws Le Chatelier. It will develop processes of effects neutralization and restore of equilibrium in order to return to the initial state [8, 15]. Steadiness of TRS depends on its buffering capacity $[1,2,20]$.

Thus, TRS that is the subject of this study is defined as the dynamic set for the purpose of recreation of anthropogenic subjects and processes within geosystems. Their activity continually influences on an environment, changes quantitative and qualitative parameters of Geosystems, and it is affected by the man-made changes. Sustainable development of TRS provides such organization of recreational activities when territorial geosystem does not go beyond the homeostasis levels and increasing of a recreational load is limited by buffering capacity of TRS.

Based on the results of previous studies generally $[3,8$, $9,12,21]$ and especially Geosystems [2, 10, 11, 14, 17], authors made a mathematical formalization of sustainable development of TRS.

TRS can be described by the relation:

$$
\begin{aligned}
& S=\{X, Q\}, \\
& X=\left\{X_{1}, X_{2}, X_{3}, \ldots, X_{n}\right\},
\end{aligned}
$$

where $Q$ - the set of patterns of the $X$ elements changing, their interaction with each other and with the environment; $X$ - elements of system $S$ in the form of a specific set of parameters; $n$ - the number of components.

The set of $X$ elements of is the content of TRS.

Elements $X_{1}, X_{2}, X_{3} \ldots, X_{n}$ are combined in the system by specific ratios and relationships that are called the framework, or, as already was mentioned above, endosystem elements. In this way natural structure of TRS is formed.

Elements of the system are interrelated and at the same time affected by external factors. Thus, exogenous system's relationships that characterize the external factors of TRS formation develop. External factors can also specify both basic material and energy flows in the recreational system of higher order, which the TRS belongs to.

Thus, TRS $(S)$ can be divided into natural $(Z)$ and anthropogenic $(W)$ subsystems with their own subsystems, elements and connections:

$$
S=Z \cdot Q \cdot W
$$

The natural subsystem is understood as a set of natural recreational resources and processes, connecting it with Geosystem. The anthropogenic subsystem is understood as 
whole the recreational complex within the TRS with all its objects and elements. It should be noticed that elements of natural and anthropogenic systems are connected by certain relations and processes which change in place and time.

Current anthropogenic variability of TRS plays an important role in terms of sustainable development. It can be specified by special prefixes: eco- and antropo-. We offer to change the eco-TRS name by antropo-TRS if the material and energy flow more than $50 \%$ altered by human activities. In both cases, it's important to allocate a percentage of natural ecosystems in TRS due to environmental factors priority on sustainable development that ensures an essential level of environmental safety, and environmental management.

Let us denote the plurality of external factors of TRS by symbol $F$. This plurality forms exogenous system's connections and are outside (surrounding) environment in relation to TRS. The set of these factors present in vector:

$$
F=\left\{F_{1}, F_{2}, F_{3}, \ldots, F_{m}\right\} \text {. }
$$

The set of relationships (links) between elements within the TRS as well as between TRS elements and environment which is called the structure of TRS (symbol $S$ ) is denoted as:

$$
R=\left\{R_{l}, R_{2}, R_{3}, \ldots R_{l}\right\}
$$

where $R_{l}$ - number of connections that form the structure of the system $S$.

As a result of this interaction process the functional structure of TRS is formed.

The composition of TRS $X$, environmental factors $F$ and the structure $R$ change in the process of sustainable development through time $t$ and space $h$. This change in the general form can be described as follows:

$$
\begin{aligned}
& X=X(t, h)=\left\{X_{1}(t, h), X_{2}(t, h), X_{3}(t, h), \ldots, X_{n}(t, h)\right\}, \\
& F=F(t, h)=\left\{F_{1}(t, h), F_{2}(t, h), F_{3}(t, h), \ldots, F_{m}(t, h)\right\}, \\
& R=R(t, h)=\left\{R_{1}(t, h), R_{2}(t, h), R_{3}(t, h), \ldots, R_{1}(t, h)\right\}
\end{aligned}
$$

Sustainable development in time and space of elements $\mathrm{X}(\mathrm{t}, \mathrm{h})$ and the structure $\mathrm{R}(\mathrm{t}, \mathrm{h})$ of TRS depend on external factors $F(t, h)$ and it follows the function $M(t, h)$.

Taking into account mathematical formalization of TRS sustainable development done by authors, it's possible to define TRS as: territorial recreational system $S(t, h)$ which functioning in the environment $F(t, h)$ is the set of objects $S$ $(t, h)=S(X, F, R, M)$, which is formed as a combination of internal elements $X(t, h)$, connecting with each other and with the environment $F(t, h)$ by set of relations $R(t, h)$ that vary in the process of sustainable development in time and space according to the set of functions $M(t, h)$ (Figure.1).

In studies of the sustainable development of TRS, it is always divided into elements - subsystems and their structure are studied. Levels of study could be different from national, regional and local to subtopical - peculiar recreational subject, which is part of bigger TRS. Example:
Lake Bukovel $\rightarrow$ Touristic Complex Bukovel $\rightarrow$ Palyanytska TRS $\rightarrow$ Carpathian TRS etc.

Each level of TRS will have indicators characterizing from the one hand, natural elements and conditions of their interaction in the system, and from the other - the intensity and principles of recreation and human activities that determine the direction and the main parameters of the system.

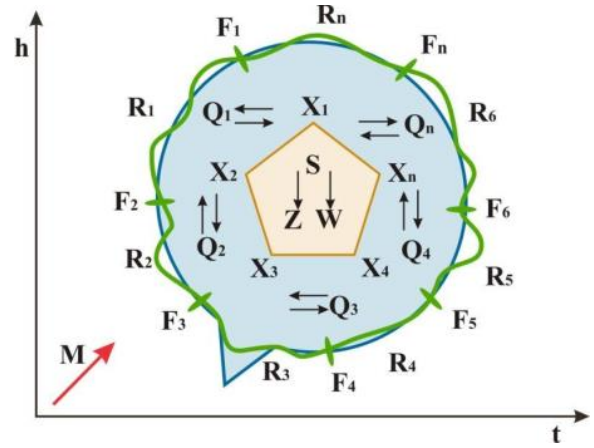

Figure 1 - Formalised model of TRS

Systems organization of recreational environment in the context of multiscale TRS functioning enables to implement different levels of sustainability management. It reflects the fact of necessity to optimize the relationship of man with the environment through a rational spatial organization of recreational activities.

As the functional features of TRS determine the ability to predict environmental processes and decision-making for sustainable development, the main procedure in systems research is to build a model that reflects the key factors and relationships of the real situation. Studying of the recreational environment formation as TRS of the different level requires analysis of a large number of items and evaluation of relations between them in terms of homeostasis maintaining within homeostasis of geosystem basis of TRS at the positive dynamic of recreation load.

Prospects of our research include conducting of package studies to elaborate another model of the recreational environment development which helps to solve an entire range of questions related to sustainability management and implement of a number of interrelated models with different framework features. The purpose of their creation is a gradual maximum possible reduction of the uncertainty of the studying systems by examining and identifying general and specific patterns of their development. The author suggests assessing the recreational load through changing potential buffer capacity.

\section{CONCLUSIONS}

In this paper, the functional properties of the recreational environment are substantiated using the example of biosphere ecological concept and ecosystem's framework approach for the sustainable development of territorial recreation systems (TRS).

In the issue of the sustainable development of TRS, its makes sense to study the dynamic processes in the prism of natural and man-made systems. Under the naturaltechnogenic system, the authors understands the dynamic spatiotemporal range of materials and processes both natural 
and anthropogenic, through which the exchange of matter and energy in the local systems, including recreation ones, occurs. According to the authors, the buffer capacity of recreation system is the dominant factor determining the prospects for the sustainable development of TRS.

According to the principle of the functional and integrated system, TRS are distinguished as the amount of space; Geosystem is its framework. The combination of theoretical and methodological foundations of the doctrine of functionally integral geosystems with the concept of multivector nature of recreational environment formation, allowed pointing out and specifying those TRS, which operate within a certain space. The authors proposed a hierarchical classification of TRS according to their size. TRS, according to the authors is a dynamic set with the purpose of anthropogenic subjects and processes recreation within Geosystems whose activities continually trigger environmental changes, quantitative and qualitative Geosystem parameters, and is under the influence of manmade changes. The sustainable development of TRS provides an organization of recreational activities in which territorial Geosystem does not go beyond homeostasis and increasing of a recreational load is limited by buffer capacity of TRS.

In this paper, the mathematical formalization of sustainable development of TRS is suggested. It can be used for the following definition of the subject of research: territorial recreational system that operates in the environment, is the set of subjects that formed from a set of internal components interconnected with each other and with the environment by set of connections which vary in the process of sustainable development in time and space according to the set of functions.

\section{REFERENCES}

[1] O.M. Mandryk, L.M.. Arkhypova, O.V. Pobigun and O.R. Maniuk, "Renewable energy sources for sustainable tourism in the Carpathian region", in IOP Conf. Series: Materials Science and Engineering , Banja Luke, 2015, Vol. 144. doi: 10.1088/1757-899X/144/1/012007

[2] M. Korchemlyuk, L. Arkhypova, "Environmental audit of Ukrainian basin ecosystem of the Prut river", Scientific Bulletin of National Mining University, No 5 (155), pp. 98-106, 2016.

[3] V.S. Preobrazhensky, Yu.A. Vedenin, I.V. Zorin, L.I. Mukhina "Territorial recreational system as object of study of geographical sciences", Izv. USSR Academy of Sciences. Avg. Geogr., No. 2, pp.13-18, 1974. [in Russian].
[4] O.V. Ilyina, "Tourism. Recreational Geography: Concepts and Terms". Lutsk, Ukraine: Teren, 2009. [in Ukrainian].

[5] I.V. Smal, "Fundamentals of Geography of Recreation and Tourism: A Handbook". Nizhyn, Ukraine: Mykola Gogol Publishing House, 2014. [in Ukrainian].

[6] O.O. Bedyk, "Ukrainian-Russian dictionary of terms and concepts in recreational and tourism geography". K., Ukraine, 1997. [in Ukrainian].

[7] I. Kinash, L. Arkhypova, A. Polyanska, O. Dzoba, U. Andrusiv and Iu. Iuras, "Economic evaluation of tourism infrastructure development in Ukraine", in IOP Conference Series: Materials Science and Engineering, Banja Luke, 2018, Vol. 477, No. 1. Available: $\quad$ https://iopscience.iop.org/article/10.1088/1757899X/477/1/012020

[8] T. Athey, "Systematic systems approach". New Jersey, USA: Johns\&Breg, 1992.

[9] Fleischaker, Gail Raney (eds), "Autopoiesis in System Analysis. A Debate”. Intern.J. of General Systems, Vol.21, pp. 134-156, 1992.

[10] V.A. Emelyanov, "Fundamentals of marine geoecology". K., Ukraine: Scientific Thought, 2013. [in Russian].

[11] V.D. Fedorov, T.G. Gilmanov, "Ecology”. Moscow, Russia: Moscow State University, 1995. [in Russian].

[12] B.S. Fleischman, "Fundamentals of Systemology". Moscow, Russia: Radio and Communication, 1992. [in Russian].

[13] G.S. Rosenberg, I.E. Smelyansky, "Ecological pendulum (paradigm shift in modern ecology)", Journal of General Biology , T. 58, No. 4, pp. 5-19, 2005. [in Russian].

[14] K.M. Khaylov, "Systematic Approach in Ecology", System Studies, T. 25, No. 3, pp. 118-122, 2010. [in Russian].

[15] C.B. Subrahmanya, "Principles of ecology". Florida, A\&M University: McGraw-Hill, 1998.

[16] Y. Odum. "Ecology: In 2 vol.”. Moscow, Russia: World, 1986. [in Russian].

[17] O. M. Mandryk, L. M. Arkhypova, A. V. Pukish, A. Zelmanovych, Kh. Yakovlyuk, "Theoretical and methodological foundations of sustainable development of Geosystems", in IOP Conf. Series: Materials Science and Engineering, Banja Luke, 2017, Vol. 200, doi: 10.1088/1757-899X/200/1/012018

[18] L.M. Arkhypova, S.V. Pernerovskaya, "Forecasting water bodies hydrological parameters using singular spectrum analysis", Naukovyi Visnyk Natsionalnoho Hirnychoho Universytetu, Vol. 2 (146), pp. 4550, 2015.

[19] P.M. Bernstyle, “Against the Gods. Taming the risk". Moscow, Russia: Olympus - Business, 2006. [in Russian].

[20] M.D. Grodzinski, "Stability of Geosystems to Anthropogenic Loads". K., Ukraine: Likey, 2005. [in Ukrainian].

[21] O.D. Duncan, "Social Organization and the Ecosystem. In: Handbook of Modern Sociology (R.E.L. - Paris, ed.)". Chicago, USA: Rand NcNally and Company, 1994. 